\title{
Study of the Diffusion Tensor Imaging for Preclinical Therapeutic Efficacy of Umbilical Cord Mesenchymal Stem Cell Transplantation in the Treatment of Spinal Cord Injury
}

Ying Zhao',*

Liqing $\mathrm{Yao}^{1, *}$

Lijuan $\mathrm{Ao}^{2}$

Jibing $\mathrm{Ou}^{\prime}$

Ying $\mathrm{He}^{\mathrm{l}}$

Yunyun Shang'

'The Second Affiliated Hospital of Kunming Medical University, Kunming, 650000, People's Republic of China;

${ }^{2}$ School of Rehabilitation, Kunming Medical University, Kunming, 650000,

People's Republic of China

*These authors contributed equally to this work
Correspondence: Lijuan Ao

School of Rehabilitation, Kunming Medical

University, Kunming, 650500, People's

Republic of China

Tel +86 |35087|008 |

Fax +8687165338994

Email lijuandrao@163.com
Objective: In this study, umbilical cord mesenchymal stem cell (UC-MSC) transplantation was used to treat patients with spinal cord injury (SCI). The microstructural changes of the spinal cord before and after transplantation were observed by diffusion tensor imaging (DTI). Methods: From January 2014 to May 2015, seven patients who met the inclusion criteria were enrolled in this study. In the experimental group, both UC-MSC transplantation and comprehensive rehabilitation treatment were applied, while the control group received only comprehensive rehabilitation treatment. American Spinal Injury Association (ASIA) sensory and motor scores and the degree of SCI, spasticity, and urine/defecation functions were measured and evaluated together with DTI before the treatment and again at two and six months after the first treatment.

Results: From the DTI, the changes in the fractional anisotropy (FA) value and the apparent diffusion coefficient (ADC) value were as follows: in the experimental group, there were significant differences in the FA and $\mathrm{ADC}$ values before and after treatment $(\mathrm{P}<0.05)$ with a decreased ADC value and an increased FA value. The differences in the ADC and FA values of the normal layer and the lesion layer before and after treatment were compared. The differences in $\mathrm{ADC}$ and FA at the lesion layer before and after transplantation were greater than those of the normal layer, and the differences were statistically significant $(\mathrm{P}<0.05)$. In the experimental group, one patient with incomplete SCI and one patient with a short course of complete SCI improved in terms of light touch, acupuncture sensation, and motor score. One patient with incomplete SCI achieved improvement in spasticity and urine/defecation functions.

Conclusion: The combination of UC-MSC transplantation and comprehensive rehabilitation therapy could help to promote the structural repair of the spinal nerve in patients with SCI. Keywords: spinal cord injury, stem cell, DTI, ADC, FA

\section{Introduction}

Spinal cord injury (SCI) is a clinical syndrome in which the structure and function of the spinal cord are damaged by injury or disease, which leads to a change in motor, sensory, and autonomic nerve function below the level of the injury. The incidence of SCI is high with great harm. Currently, the treatment of SCI mainly focuses on the following aspects: (1) Neural protection and control of the secondary injury, including hypothermia, ${ }^{1}$ surgical decompression, hormone pulse therapy, riluzole, ${ }^{2}$ and free radical scavenging. (2) Promotion of axon regeneration and 
repair of the injured myelin sheath, including cell transplantation, neuron growth factor, myelin-related inhibitor targeting agent, and galectin-1 (Gal-1). ${ }^{3}$ (3) Removal of the factors that inhibit axonal regeneration, including the application of anti-axon growth inhibitor and gene silencing to indirectly promote axon regeneration. However, due to the central nervous system's limited abilities of repair following injury in adults, the dead neurons cannot be replaced by new or adjacent neurons generated by the central nervous system itself; therefore, the therapeutic effect is limited. The rapid development of neural tissue engineering technology makes it possible to use tissue engineering cells to repair the nerve injury; this provides a new possibility for the treatment of SCI and makes it possible to repair injured axons, regenerate neurons, and restore part of the function of the spinal cord nerve. At present, the candidate cells mainly include neural stem cells (NSCs), mesenchymal stem cells (MSCs), embryonic stem cells (ESCs), umbilical cord blood stem cells, oligodendrocyte precursor cells, Schwann cells, and olfactory ensheathing cells. ${ }^{4}$ Currently, there is increasing research on the treatment of SCI with stem cell transplantation, and its therapeutic effect has been confirmed. ${ }^{5,6}$ However, there are few reports on the changes of the spinal cord fibers in vivo following stem cell transplantation.

Diffusion-weighted imaging (DWI) and diffusion tensor imaging (DTI) are two functional magnetic resonance imaging (MRI) techniques that can reflect the diffusion characteristics of water molecules in living tissue. They can dynamically provide the micro-pathophysiological structure of the spinal cord, the functional state of water molecule exchange between various components under a pathological state and show changes in fiber connections in the living spinal cord via intuitive fiber-tracing images. ${ }^{7}$ Compared with conventional MRI, DTI can evaluate the functional status of the spinal cord. It is of great benefit in the clinical study of both the location and degree of a SCI and in the evaluation of therapeutic effects and prognoses. DTI provides a new concept and method for studying the subtle structural changes of the spinal cord following stem cell transplantation.

In this study, umbilical cord mesenchymal stem cells (UCMSCs) were used in the treatment of patients with SCI. DTI was utilized to observe the correlation between the changes in spinal cord microstructure and nerve function before and after treatment. The aim of this study was to determine the preclinical changes in patients following UC-MSC treatment to provide a clear foundation for stem cell treatment in SCI.

\section{Materials and Methods}

\section{Patients}

From January 2014 to May 2015, the inclusion criteria for patients with SCI who were admitted to the authors' department were as follows: (1) patients with a first diagnosis of complete SCI (ASIA grade A) or incomplete SCI (ASIA grades $\mathrm{B}-\mathrm{D})$ according to International Classification of Diseases, Ninth Revision (ICD-9), (2) patients with SCI involving the cervical, thoracic, and lumbar segments, (3) patients aged between 18 50 years, (4) patients with a course of SCI of 1 month $\sim 5$ years, and (5) patients who were hospitalized for comprehensive rehabilitation treatment for one month or more. This study was conducted in accordance with the Declaration of Helsinki. Following examination and the approval of the Medical Ethics Committee of the hospital, patients were informed about the study and follow-up; they agreed to participate and gave informed consent. The flow diagram was showed in Figure 1.

The exclusion criteria were as follows: (1) patients with a magnetic metal foreign body or pacemaker, (2) patients with uncontrollable severe infection and high fever, (3) patients with complex trauma, such as brain trauma and thoracic-abdominal trauma, (4) patients with peripheral nerve injury, such as a brachial plexus injury, limb fracture, or hypersensitivity, who could not complete the examination, (5) patients with cardiac, pulmonary, hepatic, renal, and other important organ dysfunctions and mental diseases, (6) patients with coagulation dysfunction, and (7) patients under 18 years old or above 50 years old. The withdrawal criteria were as follows: (1) patients who died, changed treatment, transferred, or who did not attend the follow-up, and (2) patients who terminated the treatment due to serious adverse reactions. The Medical Ethics Committee of The second affiliated hospital of Kunming Medical University approved the UC-MSC transplantation treatment, which was placed on record in the superior health administrative department and was performed with the informed consent of patients.

\section{Grouping Methods}

The Experimental Group

Patients with SCI who met the inclusion criteria were educated on stem cell therapy technology. Patients who voluntarily chose UC-MSC transplantation therapy technology signed the informed consent form for stem cell transplantation. Those who were willing to cooperate with the DTI examination signed the informed consent 


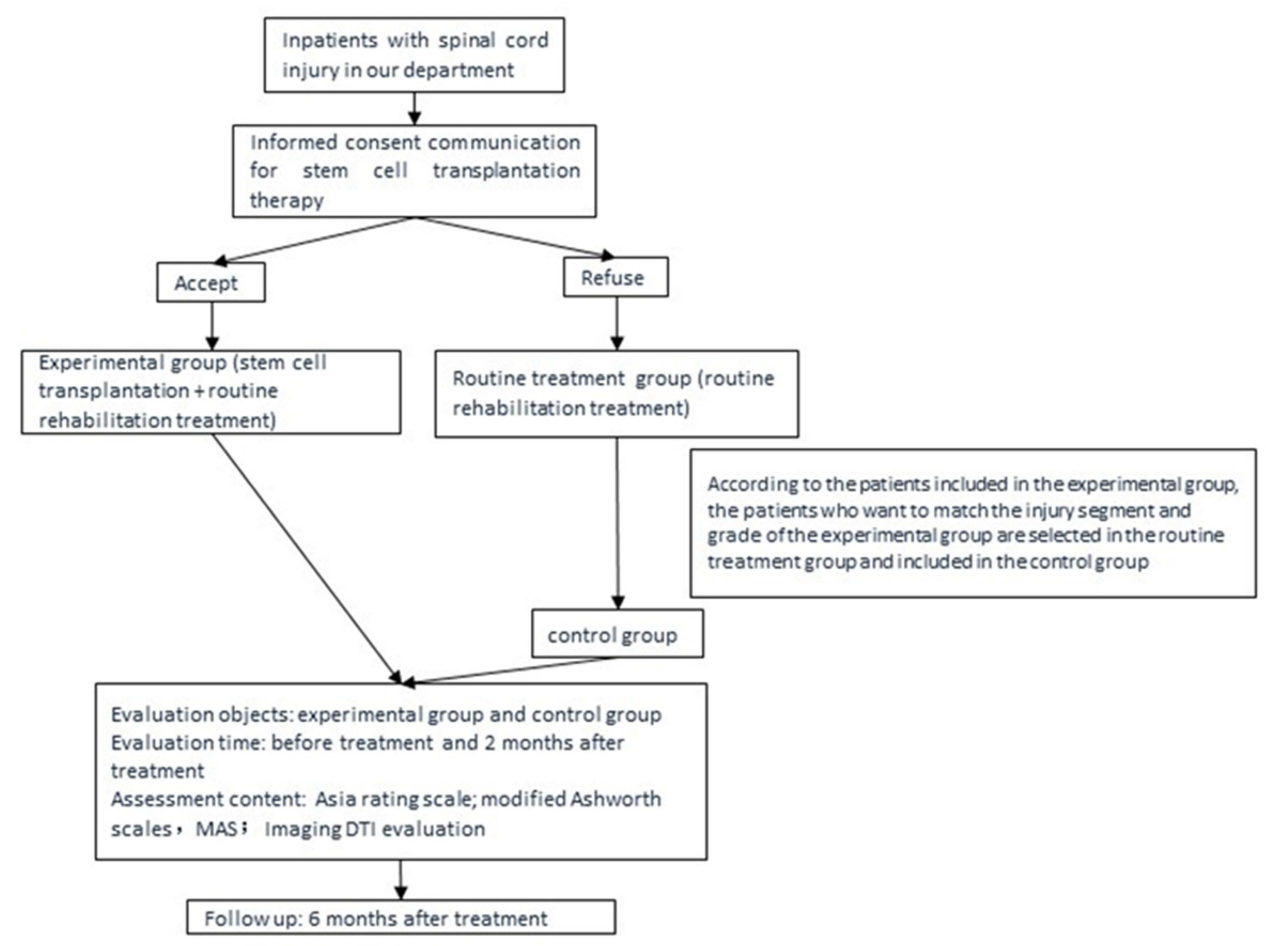

Figure I The flow diagram on the study population selection and evaluation.

form for the DTI research project and were included in the experimental group. Stem cell therapy and comprehensive rehabilitation treatment were applied to this group.

\section{The Control Group}

Patients who met the inclusion criteria and were not willing to receive UC-MSC treatment but who were willing to undergo DTI signed the informed consent form for the DTI research project and were included in the control group. Comprehensive rehabilitation treatment was given to this cohort.

\section{Main Apparatus and Evaluation Method in Diffusion Tensor Imaging}

The study used a Siemens Sonata $1.5 \mathrm{~T}$ superconducting MR scanner. MRI scanning was performed using 8-channel memorized phased-array coils, and a Leonardo graphic image workstation was used. The apparent diffusion coefficient (ADC) and fractional anisotropy (FA) values were measured using post-processing software.

\section{Routine MRI Scanning of Spinal Cord}

All patients underwent localization scanning with fast spoiled gradient echo, and sagittal T2 weighted imaging (T2WI) and T1 weighted imaging (T1WI) scanning were completed with fast spin echo (FSE). Scanning parameter T2WI: repetition time (TR): $3280 \mathrm{~ms}$, echo time (TE) 98 ms; T1WI: TR501 ms, TE $11 \mathrm{~ms}$, layer thickness $3.0 \mathrm{~mm}$, field of view (FOV) $280 \mathrm{~mm} \times 250 \mathrm{~mm}$.

After scanning, the DTI images were transferred to the Siemens workstation for post processing. DTI images of the sagittal position of the spinal cord were generated, including $\mathrm{ADC}$ and FA images. In the zoom and 3D modes of the DTI post-processing window, the most commonly used region of interest (ROI) method was utilized to extract and evaluate the DTI parameters. ${ }^{8}$ An ROI of the same size (about 2-3 pixels) in the selected layer was placed in the center of the lesion area of the spinal cord. The ROI was copied and pasted with the anatomical image to ensure accurate positioning. The ADC and FA values were measured by the analysis software provided by the equipment. Between six and seven groups of ADC and FA values were generated in each patient (Figure 2).

\section{Therapeutic Method of Stem Cell Transplantation Stem Cell Source/Type}

The stem cells were provided by Shenzhen Beike Stem Cell Biotechnology Co., Ltd. and were of the UC-MSC type (Figure 3). All the infused UC-MSCs were from 

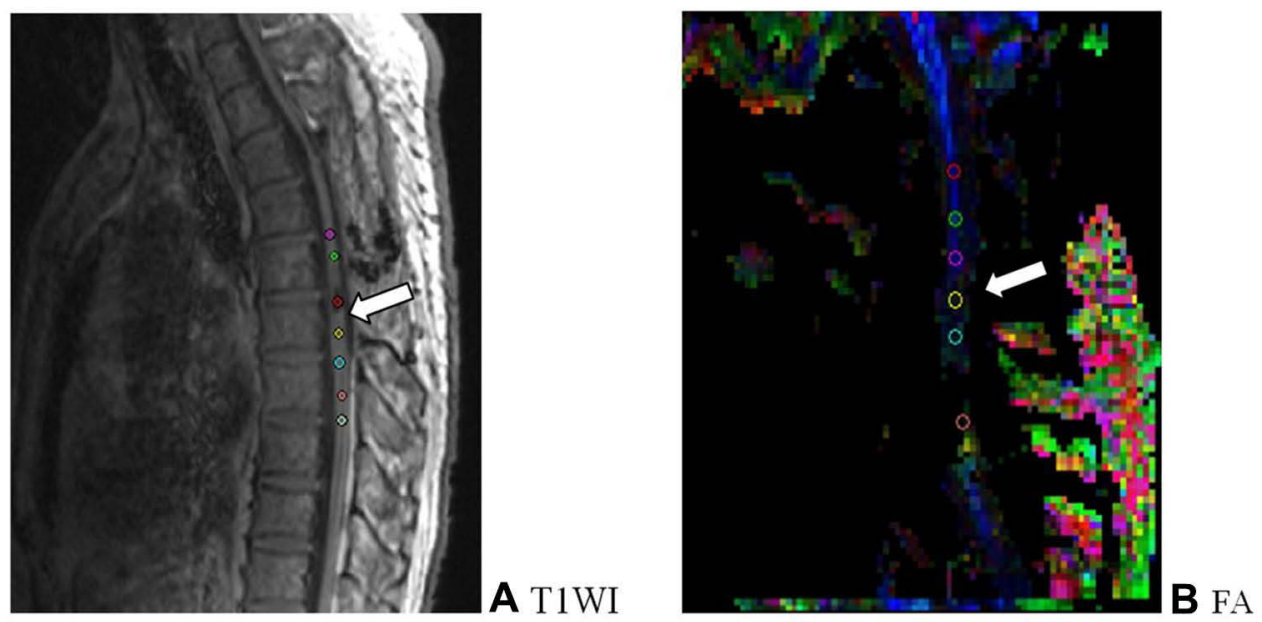

Positioning site of ROI

Figure 2 Positioning site of ROI. (A) TIWI image; (B) FA image. TIWI showed FA was a DTI scalar, representing axon integrity and closely related to fiber integrity.

the second to the fifth generations and underwent strict purification and quality control procedures.

\section{Methods of Transplantation}

The stem cell transplantation was performed once a week for four weeks as a course of treatment. The transplantation route was as follows: In the first week, $30 \mathrm{~mL}$ of UC-MSCs (including the plasma) was injected intravenously at the rate of 40-60 drops for a minutes before $5 \mathrm{mg}$ of dexamethasone was given. Intrathecal injection was performed during the last three weeks. Left knee flexion was taken in the patients, and the injection location was at the L3/4 or L4/5 intervertebral space. After local disinfection, local infiltration anesthesia with $2 \%$ of lidocaine was administered at the puncture point and was covered with a hole towel. Then,

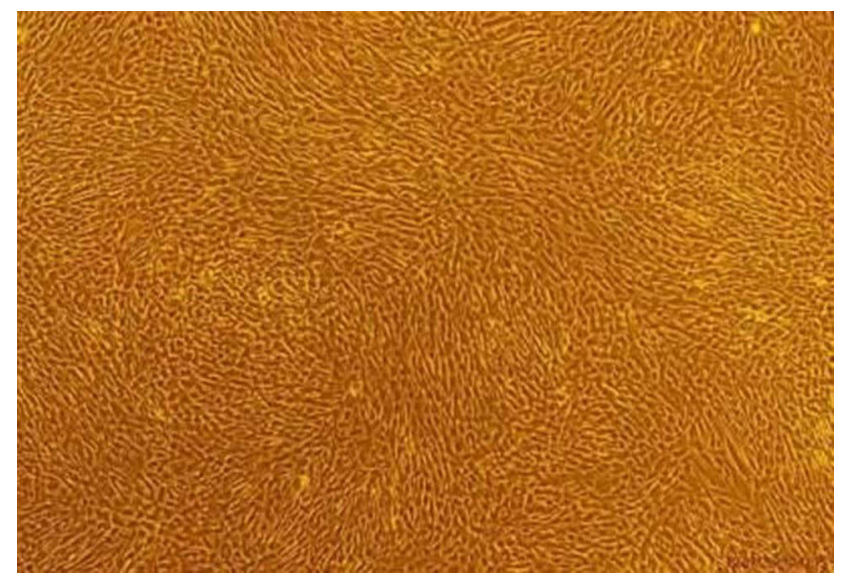

Figure 3 The cell morphology under $4 x$ microscope for the fourth generation cells. a No. 9 or 7 lumbar puncture needle was used to puncture into the epidural space from the intervertebral space; the needle entry continued until there was a sense of falling, then the core of the needle was removed. With clear cerebrospinal fluid flowing out, the piezometric tube was connected to measure the pressure, and $8-9 \mathrm{~mL}$ of the cerebrospinal fluid was drawn for analysis. Then, $1.0 \mathrm{~mL}$ of the UC-MSC and $8-9 \mathrm{~mL}$ of $0.9 \%$ normal saline were injected into the subarachnoid space via a $10-\mathrm{mL}$ syringe. The number of cells was $5 \times 10^{7} / 1$. Following the operation, the patients remained supine for six hours without a pillow.

\section{Comprehensive Rehabilitation Therapy}

The duration of the comprehensive rehabilitation treatment was at least one month. According to the degree of injury, spinal stability, and functional status of the patients, the comprehensive rehabilitation treatment included drug nutrition, microcirculation improvement, muscle strength training, traction, endurance training, sitting and standing balance training, maintaining and expanding the range of joint activities, transfer training, wheelchair skills training, daily living activities training, limb massage, acupuncture, physical therapy or functional electrical stimulation, magnetic bed treatment, and application of orthosis.

\section{Evaluation of the Clinical Effects}

In both the experimental and control groups, the ASIA rating scale was assessed before treatment and again at two and six months after the first treatment. Spasm was 
evaluated by the modified Ashworth scales (MAS), and DTI was performed.

\section{Spinal Cord DTI Scanning}

Sagittal imaging of spinal cord was performed by single shot spin echo plane sequence (SE-EPI), all using automatic shimming and lipid suppression techniques. The scanning plane was the same as the conventional sagittal plane. Diffusion sensitive gradient took 12 directions, parameters: TR 2400 $\mathrm{ms}$, TE $74 \mathrm{~ms}$, FOV $280 \mathrm{~mm} \times 280 \mathrm{~mm}$, matrix $120 \times 128$, the layer thickness was $3.0 \mathrm{~mm}$, the layer spacing was 0 , the number of layers was 20 , and the diffusion weighting coefficient values are 0 and $500 \mathrm{~s} / \mathrm{mm}^{2}$, respectively.

\section{Observation of Safety Indices and Adverse Reactions}

After the treatment, the patients' vital signs were closely observed, and changes in routine blood test, coagulation function, and hepatic and renal functions were compared with the before-treatment results. The routine examination and biochemical changes of the cerebrospinal fluid extracted in each treatment were observed, and the occurrence of adverse reactions at any time was recorded.

\section{Statistical Methods}

Due to the small number of cases collected in this study, the general data of the patients and that of the clinical evaluation could not be statistically analyzed; therefore, a case analysis was conducted. The ADC and FA values were statistically analyzed using SPSS 17.0 software and were expressed as mean \pm standard deviation $(\overline{\mathrm{x}} \pm \mathrm{s})$. A normality test and a homogeneity test of variance were conducted, and a paired $t$-test was applied for comparison before and after treatment in patients with normal distribution and homogeneous variance. The value $(P<0.05)$ was considered to be statistically significant.

\section{Results}

\section{Analysis of the Participants The Experimental Group}

From January 2014 to May 2015, a total of 16 patients with SCI were treated in the authors' department with stem cell transplantation; 10 of these patients met the requirements for the MRI examination. During the process of inclusion, two patients refused to participate in the experiment, eight patients underwent MRI and DTI examinations, and four patients lost the follow-up (the main reason was that they were no longer willing to undergo the examination after discharge). Of the remaining four patients, two cases were followed up for eight weeks and two were followed up for 24 weeks (all calculated from the time of the first treatment).

\section{The Control Group}

After the experimental group was confirmed, the control group was paired. According to the principle of matching the injured segments (the cervical segment, the thoracic segment, and the lumbar segment) and the injury level (ASIA: A-D), eight cases were included in the control group. Five of these were withdrawn, and three were followed up for eight weeks.

\section{Analysis of the Clinical Symptoms of the Study Subjects}

1. The seven subjects comprised six patients with complete injuries and one with incomplete injuries (Table 1). Among the six patients with complete injuries, a descent of two segments of nerve level was achieved in one patient who received stem cell transplantation. The remaining two patients who received stem cell intervention and the three patients who did not receive stem cell intervention did not make progress in spasticity and urine/defecation control. One patient with an incomplete injury who received stem cell transplantation intervention showed improvements in spasticity and urine/defecation control (Table 2).

2. Among the four patients in the experimental group, one patient with an incomplete injury and one patient with a complete injury showed improvements in acupuncture sensation, light touch, and motor scores after two months of treatment and improved significantly after six months of treatment. There were no obvious changes in the other two patients (Table 3). A paired $t$-test was used to compare the experimental group's acupuncture sensation, light touch, and motor scores before the treatment and at two and six months after the treatment, respectively. The results showed no statistical significance $(P>0.05)$ (Table 4).

\section{Results of Diffusion Tensor Imaging Fractional Anisotropy and Apparent Diffusion Coefficient Images}

In the FA image, the direction of the white matter fiber was represented by color, blue represented the up and down directions, green represented the front and back directions, and red 
Table I General Information of Patients

\begin{tabular}{|c|c|c|c|c|c|c|c|}
\hline Case & Genders & Age & $\begin{array}{l}\text { Course of } \\
\text { Disease } \\
\text { (Month) }\end{array}$ & Diagnostic & $\begin{array}{l}\text { Modified } \\
\text { Ashworth } \\
\text { Score }\end{array}$ & $\begin{array}{l}\text { Urination and } \\
\text { Defecation }\end{array}$ & Treatment Options \\
\hline I & Male & 47 & 19 & $\begin{array}{c}\text { T6 Spinal Cord Injury } \\
\text { Grade C }\end{array}$ & III & $\begin{array}{l}\text { Self-control, } \\
\text { about } 50 \mathrm{~mL} \text { of } \\
\text { residual urine }\end{array}$ & $\begin{array}{l}\text { Umbilical Cord Mesenchymal Stem Cell } \\
\text { Transplantation + Comprehensive } \\
\text { Rehabilitation Therapy }\end{array}$ \\
\hline 2 & Male & 43 & 9 & $\begin{array}{c}\text { C4 Spinal Cord Injury } \\
\text { Grade A }\end{array}$ & II-III & Incontinence & $\begin{array}{l}\text { Umbilical Cord Mesenchymal Stem Cell } \\
\text { Transplantation + Comprehensive } \\
\text { Rehabilitation Therapy }\end{array}$ \\
\hline 3 & Male & 22 & 6 & $\begin{array}{c}\text { C6 Spinal Cord Injury } \\
\text { Grade A }\end{array}$ & 0 & Incontinence & $\begin{array}{l}\text { Umbilical Cord Mesenchymal Stem Cell } \\
\text { Transplantation + Comprehensive } \\
\text { Rehabilitation Therapy }\end{array}$ \\
\hline 4 & Female & 29 & 2 & $\begin{array}{c}\text { TI0 Spinal Cord Injury } \\
\text { Grade A }\end{array}$ & $\mathrm{I}$ & Incontinence & $\begin{array}{l}\text { Umbilical Cord Mesenchymal Stem Cell } \\
\text { Transplantation + Comprehensive } \\
\text { Rehabilitation Therapy }\end{array}$ \\
\hline 5 & Male & 27 & I & $\begin{array}{c}\text { TI2 Spinal Cord Injury } \\
\text { Grade A }\end{array}$ & 0 & Incontinence & Comprehensive rehabilitation therapy \\
\hline 6 & Male & 24 & 5 & $\begin{array}{c}\text { T8 Spinal Cord Injury } \\
\text { Grade A }\end{array}$ & $\mathrm{I}^{+}$ & Incontinence & Comprehensive rehabilitation therapy \\
\hline 7 & Male & 35 & 10 & $\begin{array}{c}\text { C7 Spinal Cord Injury } \\
\text { Grade A }\end{array}$ & II & Incontinence & Comprehensive rehabilitation therapy \\
\hline
\end{tabular}

Table 2 Comparison of Spasticity and Urination and Defecation in the Experimental and Control Groups Before and 2 Months After Treatment

\begin{tabular}{|c|c|c|c|c|c|c|c|c|c|c|}
\hline \multirow[t]{2}{*}{ Case } & \multicolumn{2}{|c|}{$\begin{array}{c}\text { Bilateral Lower Limb } \\
\text { MAS Score }\end{array}$} & \multicolumn{2}{|c|}{ Achilles Tendon Reflex } & \multicolumn{2}{|c|}{ Ankle Spasm } & \multicolumn{2}{|c|}{ Babinski Test } & \multicolumn{2}{|c|}{ Urination and Defecation } \\
\hline & $\begin{array}{c}\text { Before } \\
\text { Treatment }\end{array}$ & $\begin{array}{c}\text { After } \\
\text { Treatment }\end{array}$ & $\begin{array}{c}\text { Before } \\
\text { Treatment }\end{array}$ & $\begin{array}{c}\text { After } \\
\text { Treatment }\end{array}$ & $\begin{array}{c}\text { Before } \\
\text { Treatment }\end{array}$ & $\begin{array}{c}\text { After } \\
\text { Treatment }\end{array}$ & $\begin{array}{c}\text { Before } \\
\text { Treatment }\end{array}$ & $\begin{array}{c}\text { After } \\
\text { Treatment }\end{array}$ & $\begin{array}{c}\text { Before } \\
\text { Treatment }\end{array}$ & $\begin{array}{c}\text { After } \\
\text { Treatment }\end{array}$ \\
\hline 1 & III & $I^{+}-11$ & ++++ & +++ & + & + & + & + & $\begin{array}{l}\text { Self-control, } \\
\text { residual urine } \\
\qquad 80 \mathrm{~mL}\end{array}$ & $\begin{array}{l}\text { Self-control, } \\
\text { residual urine } \\
50 \mathrm{~mL}\end{array}$ \\
\hline 2 & II-III & $\|-I I I$ & ++++ & ++++ & + & + & + & + & Incontinence & Incontinence \\
\hline 3 & 0 & 1 & 0 & + & - & - & - & + & Incontinence & Incontinence \\
\hline 4 & 1 & I & +++ & +++ & - & - & + & + & Incontinence & Incontinence \\
\hline 5 & 0 & 0 & 0 & 0 & - & - & - & + & Incontinence & Incontinence \\
\hline 6 & $\mathrm{I}^{+}$ & $\mathrm{I}^{+}$ & +++ & +++ & - & - & + & + & Incontinence & Incontinence \\
\hline 7 & ॥ & II & ++++ & ++++ & + & + & + & + & Incontinence & Incontinence \\
\hline
\end{tabular}

Table 3 Comparison of ASIA Scores in the Experimental Group of Patients Before and After Treatment $(\overline{\mathrm{x}} \pm \mathrm{s})$

\begin{tabular}{|c|c|c|c|c|c|c|c|c|c|c|c|}
\hline \multirow[t]{2}{*}{ Case } & \multirow[t]{2}{*}{ Genders } & \multirow[t]{2}{*}{ Age } & \multicolumn{3}{|c|}{ Before Treatment } & \multicolumn{3}{|c|}{2 Months After Treatment } & \multicolumn{3}{|c|}{6 Months After Treatment } \\
\hline & & & $\begin{array}{c}\text { Sensation of } \\
\text { Needles }\end{array}$ & $\begin{array}{l}\text { Light } \\
\text { Touch }\end{array}$ & Sports & $\begin{array}{c}\text { Sensation of } \\
\text { Needles }\end{array}$ & $\begin{array}{l}\text { Light } \\
\text { Touch }\end{array}$ & Sports & $\begin{array}{c}\text { Sensation of } \\
\text { Needles }\end{array}$ & $\begin{array}{l}\text { Light } \\
\text { Touch }\end{array}$ & Sports \\
\hline 1 & Male & 47 & 77 & 78 & 72 & 79 & 80 & 80 & 82 & 83 & 86 \\
\hline 2 & Male & 43 & 14 & 16 & 20 & 14 & 15 & 21 & 14 & 16 & 22 \\
\hline 3 & Male & 22 & 58 & 61 & 16 & 57 & 61 & 18 & 57 & 60 & 18 \\
\hline 4 & Female & 29 & 71 & 72 & 60 & 78 & 78 & 66 & 78 & 78 & 68 \\
\hline
\end{tabular}


Table 4 Comparison of the ASIA Scores Before and After Treatment

\begin{tabular}{|l|c|c|c|c|c|}
\hline Targets & Before Treatment & 2 Months After Treatment & 6 Months After Treatment & t & P \\
\hline Sensation of needles & $55.00 \pm 28.46$ & $56.75 \pm 29.95$ & $57.06 \pm 30.01$ & -1.000 & 0.391 \\
Light touch & $56.25 \pm 27.71$ & $57.50 \pm 29.01$ & $58.20 \pm 29.36$ & -0.547 & 0.623 \\
Sports & $42.00 \pm 28.19$ & $43.50 \pm 27.16$ & $44.13 \pm 27.23$ & -2.324 & 0.103 \\
\hline
\end{tabular}

represented the left and right directions. The normal spinal cord was a uniform blue color, and the color of the cerebrospinal fluid was black. In the ADC image, the normal spinal cord showed a homogeneous and continuous low signal, while the signal from the cerebrospinal fluid was high.

1. In the present study, the DTI of the seven patients clearly displayed the spinal cord without obvious image distortion. In the FA images of the six patients with complete injury, there were obvious green or red abnormal signal opacities in the blue spinal cord, and the black color of the blue spinal cord interruption was visible. Some of the signals in the ADC images were increased and showed light gray, gray-white, or even white color changes; some signals were missing and showed as pure black, indicating that the continuity of the upper and lower cervical spinal cord was partially or completely interrupted. Compared with the images before the treatment and at two months following the stem cell transplantation and comprehensive rehabilitation treatment, no significant changes were found (Figure 4).

2. In one patient with incomplete injury, the DTI showed the spinal cord clearly without obvious image distortion. The FA images revealed some green or red abnormal signal opacities in the blue spinal cord without interruption of the blue spinal cord. The ADC image demonstrated a partially increased signal and showed light gray or white changes without an interruption signal. Compared with the DTI images obtained before the treatment and at two months after stem cell transplantation and comprehensive rehabilitation, it was found that the green part was slightly reduced in the FA images, and there was no significant change in the ADC image (Figure 5).

\section{Apparent Diffusion Coefficient and Fractional Anisotropy Values \\ Comparison Before and After Treatment in the Experimental Group}

The location of the spinal cord lesions was taken as the center in the four patients in the experimental group, and the ROI was taken at half of the vertebral body interval. The ADC and FA values were measured, respectively. A total of 27 groups of ADC value data and 27 groups of FA value data were obtained. The data were in accordance with a normal distribution. A paired $t$-test was performed to compare the changing tendency of the ADC and FA values before and after treatment. It was demonstrated that after two months of treatment, the ADC value was lower than before the treatment, while the FA value was higher than before the treatment. This difference was statistically significant $(P<0.05)$ (Table 5$)$.

\section{Comparison Before and After Treatment in the Control Group}

The location of the spinal cord lesions was taken as the center in the three patients in the control group, and the ROI was taken at half of the vertebral body interval. The ADC and FA values were measured, respectively. A total of 20 groups of ADC value data and 20 groups of FA value data were obtained. The data were in accordance with a normal distribution. A paired $t$-test showed that the differences in the ADC and FA values of the control group before and after treatment were not statistically significant $(\mathrm{P}>0.05)$ (Table 5).

Comparison of the ADC and FA Values Between the Lesion Site and the Normal Site Before and After the Treatment in the Experimental Group

The regions with normal signals in the T2W1 and the DTI images were taken as the center in the four patients in the experimental group. An ROI was taken from every half of the vertebral body, and the ADC and FA values were measured, respectively. The changes in the $\mathrm{ADC}$ and $\mathrm{FA}$ values before and after treatment were regarded as the ADC difference and the FA difference, respectively. A rank-sum test was used to analyze the difference in $\mathrm{ADC}$ and $\mathrm{FA}$ at both the normal level and the lesion level. The results showed that the ADC and FA differences of the injured layer were higher than those 

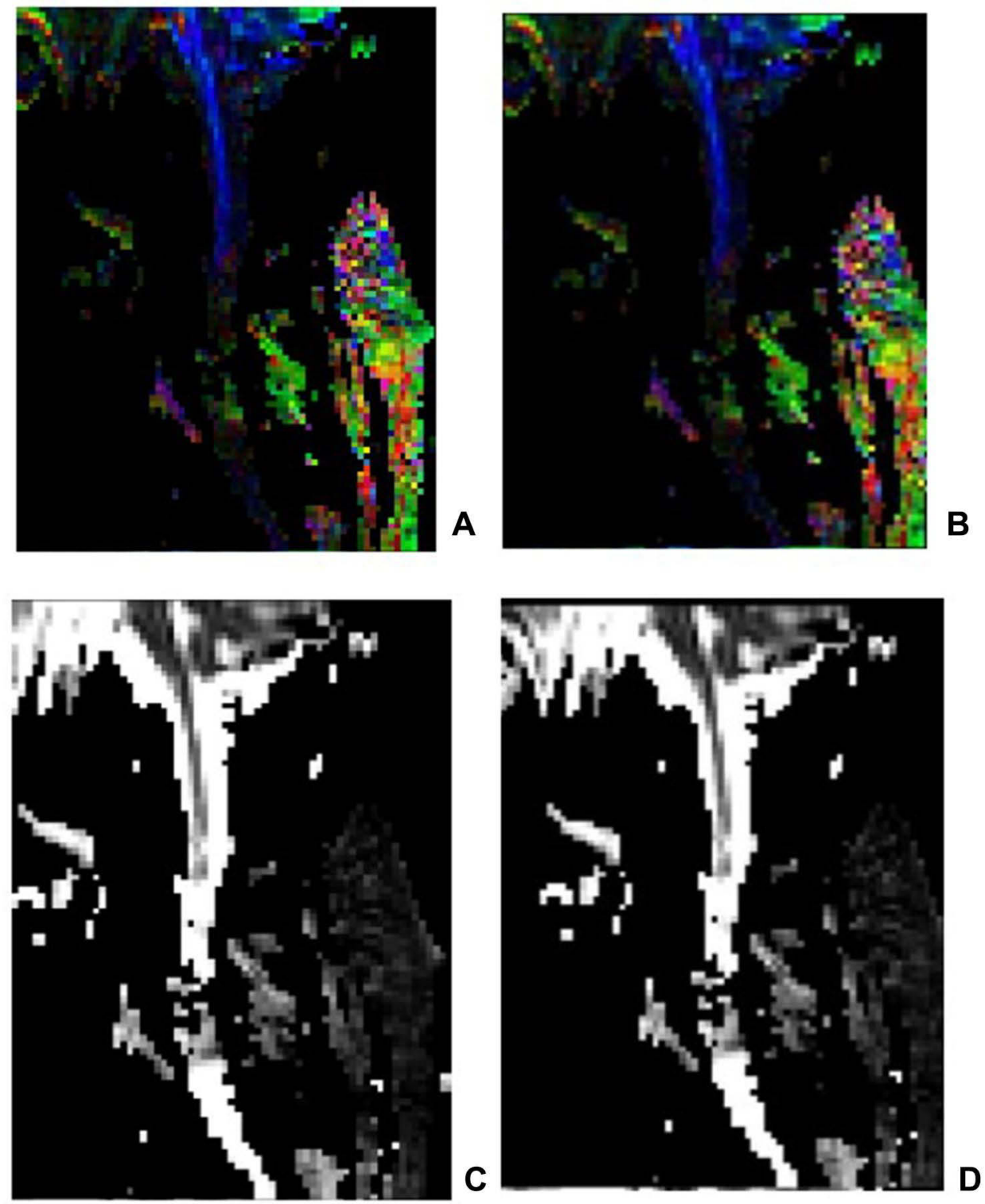

Figure 4 The FA image and the ADC image in a patient with complete cervical SCl. (A) FA image before the treatment; (B) FA image after the treatment; (C) ADC image before the treatment; (D) ADC image after the treatment. After scanning, DTI images were transmitted to Siemens workstation for post-processing to generate sagittal DTI images of spinal cord, including ADC and FA images. In the zoom and 3D mode of DTI post-processing window, ROI of the same size (about $2 \sim 3$ pixels) was placed in the center of the spinal cord lesion area at the selected spinal cord level, and the ADC value and FA value were measured.

of the normal layer before and after transplantation, and the differences were statistically significant $(P<0.05)$ (Table 6).

\section{Safety Indices and Adverse Reactions}

No abnormal changes were recorded in the routine blood test, coagulation function, and hepatic and renal functions before and after the stem cell transplantation in the experimental group. Clear yellow cerebrospinal fluid was found in one female patient during the second stem cell transplantation, but there were no abnormalities found in the routine test and biochemical assay of the cerebrospinal fluid. One patient developed a headache and a low fever after the treatment, and the symptoms were relieved on the second day without special treatment.

\section{Discussion}

\section{Stem Cells and the Therapeutic Mechanism for Spinal Cord Injury}

Stem cells are cell populations with the potential for selfrenewal, high proliferation, and multi-directional differentiation. They are the original cells of animal organisms and various tissues and organs. According to their 

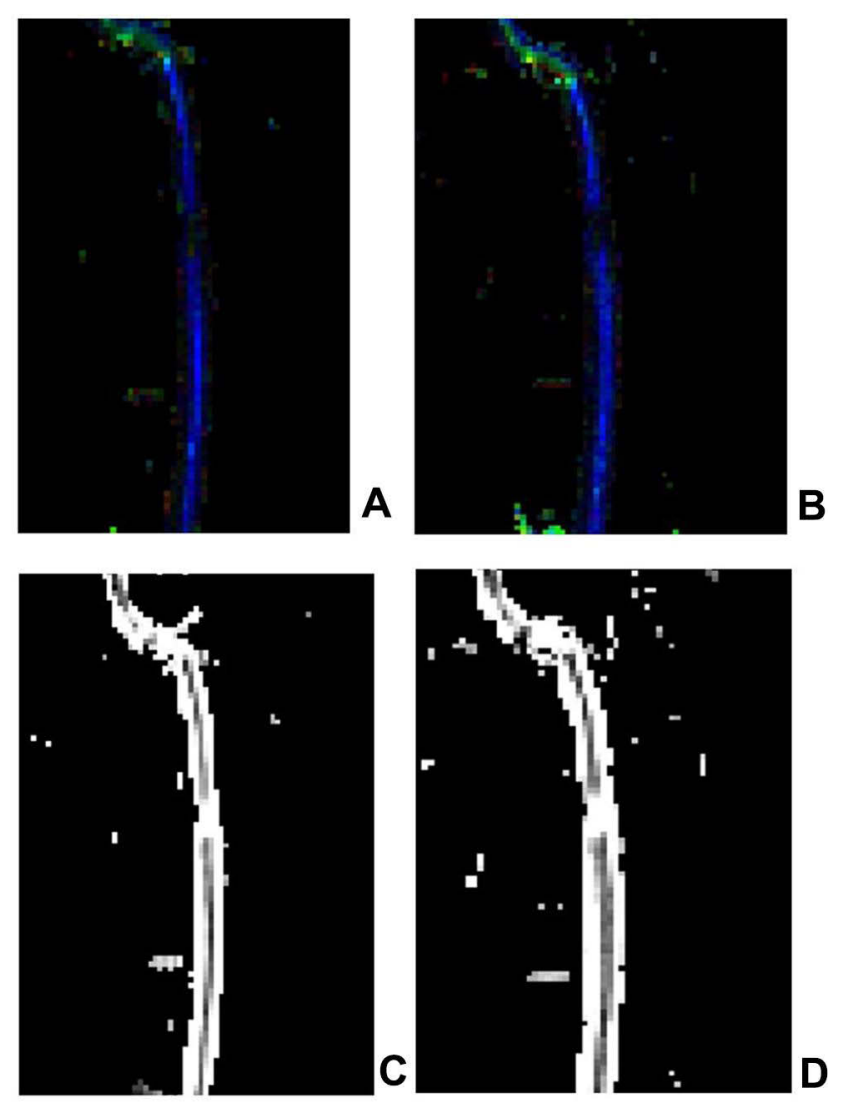

Figure 5 The FA image and the ADC image in a patient with incomplete thoracic $\mathrm{SCl}$ (A) FA image before the treatment; (B) FA image after the treatment; some green or red abnormal signal opacities could be observed in the blue spinal cord without interruption of the blue spinal cord. (C) ADC image before the treatment; (D) ADC image after the treatment. A partially increased signal and light gray or white changes without an interruption signal could be observed in the ADC image.

origins, stem cells can be divided into two categories: ESCs and adult stem cells (ASCs). ASCs include stem cells from fetal, neonatal, and adult tissues. Over the past decade, the stem cells used in the treatment of SCI have mainly included ESCs, ${ }^{9,10} \mathrm{NSCs}^{11}{ }^{11} \mathrm{MSCs},{ }^{12}$ induced pluripotent stem cells, ${ }^{13}$ and spermatogonial stem cells. $^{14}$ These can live in the host spinal cord for a certain period of time and promote the recovery of the motor function of the spinal cord to different degrees. Due to their omnipotence, ESCs have the greatest therapeutic potential for cell transplantation of all stem cells. ESCs can proliferate infinitely without aging and can differentiate into neurons and glial cells to supplement neural cell loss caused by SCI. Combined with their secretion of active factors, ESCs can inhibit the further expansion of injury and support the regeneration of nerve tissue to achieve repair in SCI. ${ }^{9}$ However, the technology of culturing ESCs is complex, and it involves ethical issues. After transplantation, ESCs possess characteristics of tumorigenesis ${ }^{15}$ and rejection; they maintain characteristics of undifferentiation or of mainly differentiating into glial cells following transplantation into the non-neural areas of the mature central nervous system, ${ }^{16}$ which limits their clinical application.

MSCs are a type of pluripotent stem cell. At present, bone marrow stem cells and adipose stem cells are mostly used in large amounts, because the survival rate and differentiation rate of these stem cells are low. ${ }^{17,18}$ They have no ethical issues and can be auto-transplanted without immune rejection. Additionally, MSCs migrate to injured and inflamed sites. However, MSCs must be obtained via invasive methods, and the number of stem cells decrease significantly with age. Thus, it is difficult to isolate and culture MSCs. The number of MSCs is insufficient to meet the needs of clinical transplantation. In recent years, MSCs have also been found in fetal accessories, such as the placenta, umbilical cord, and cord blood. UC-MSCs have the unique advantages of low immunogenicity, high proliferation, strong differentiation potential, and convenient source. Therefore, the present study selected UC-MSCs for transplantation in the treatment of SCI. The injection of stem cells into the nervous system is basically based on lumbar puncture transplantation, but for safety reasons, we gave intravenous transplantation for the first time to rule out whether there would be allergy.

A large number of studies have shown that the mechanism of MSCs in the treatment of SCI may be closely correlated with anti-inflammatory, immunomodulatory, neurotrophic, anti-apoptotic, and angiogenic effects, ${ }^{19-21}$ while the substitution effect of differentiation

Table 5 Comparison of Lesion Levels in Experimental and Control Patients Before and After Transplantation $(\bar{x} \pm S)$ ADC( $\bar{x} \pm s \times 10^{-6}$ $\left.\mathrm{mm}^{2} / \mathrm{S}\right) \mathrm{FA}\left(\overline{\mathrm{x}} \pm \mathrm{s} \times 10^{-3}\right)$

\begin{tabular}{|l|l|l|l|l|l|}
\hline & Targets & Before Transplantation & 2 Months Post-Transplant & t & P \\
\hline Experimental group & ADC & $2582.50 \pm 856.80$ & $2201.92 \pm 762.82$ & 3.951 & 0.002 \\
& FA & $208.17 \pm \mid 21.86$ & $293.67 \pm 140.91$ & -4.532 & 0.001 \\
Control group & ADC & $2640.40 \pm 208.91$ & $2710.00 \pm 351.24$ & -0.562 & 0.604 \\
& FA & $262.60 \pm 74.59$ & $293.40 \pm 40.16$ & -0.967 & 0.388 \\
\hline
\end{tabular}


Table 6 Comparison of the Difference Between Lesion Level and Normal Level in the Experimental Group of Patients Before and After Transplantation $(M \pm Q) A D C\left(M \pm Q \times 10^{-6} \mathrm{~mm}^{2} / S\right) F A(M$ $\pm \mathrm{Q} \times 10^{-3}$ )

\begin{tabular}{|l|c|c|c|c|}
\hline Targets & Lesion Level & Normal Level & $\mathbf{Z}$ & $\mathbf{P}$ \\
\hline ADC & $259.5 \pm 396.5$ & $75.0 \pm 116.2$ & -2.044 & 0.041 \\
FA & $-68.5 \pm-172.7$ & $-7.00 \pm-89.5$ & -2.326 & 0.032 \\
\hline
\end{tabular}

is not obvious. ${ }^{22}$ The difficulties in the treatment of SCI lie in how to replace the dead cells, including neurons and oligodendrocytes, how to reduce and fill the syringomyelia caused by injury, how to provide an environment for axon growth, and how to promote functional recovery. Stem cells could have the following effects: (1) bridging the broken ends in SCI to form functional synapses and reestablishing the nerve conduction pathway, (2) secreting a variety of neurotrophic factors to improve the local microenvironment of the spinal cord and initiating the sequential expression of regeneration-related genes, thus promoting axon regeneration, (3) re-sheathing the injured demyelinating axons and restoring the electrical conduction function of myelinated nerves, ${ }^{23}$ and (4) inhibiting oxidative stress, thereby reducing inflammatory reaction and increasing the inhibition of further SCI.

\section{Analysis of Clinical Effects}

Clinically, SCI usually manifests in various motor sensory and sphincter dysfunctions, dystonia, and pathological reflexes in the corresponding injured segment. This study used the MAS score, Achilles tendon reflex, ankle clonus, and Babinski test to comprehensively evaluate the overall spasticity of the lower limbs in patients with SCI. B-type ultrasonography was used to detect residual urine after spontaneous urination to preliminarily determine sphincter function. Improvements in spasticity and urine/defecation functions after stem cell transplantation were evident in only one patient with incomplete injury. The three other patients in the experimental group and the three patients in the control group did not make any progress in spasticity and urine/defecation functions.

The degree of SCI and the recovery of the motor and sensory injury can be better reflected using the ASIA score, which is currently the most sensitive method for evaluating the neurological function of SCI. By evaluating the clinical efficacy in the seven subjects in this study, it was found that the patients in the experimental group showed clinical changes both before and after treatment. Among them, one patient with incomplete injury improved in spasticity, urine/defecation functions, and ASIA score after the treatment. The injured segments in another patient in the experimental group decreased by two segments after the treatment, and their ASIA scores improved for light touch, acupuncture sensation, and movement. However, following treatment, the three patients in the control group failed to make progress in spasticity, urine/ defecation functions, and ASIA scores. Some researchers found that the transplantation of bone marrow MSCs had an obvious therapeutic effect on acute and sub-acute SCI, but there was almost no therapeutic effect on chronic SCI. ${ }^{24}$ Similarly, the only patient with a complete injury who demonstrated significant clinical changes in the present study received stem cell transplantation with a course of SCI of only one month. Thus, it could be speculated that for patients with both a short course of SCI and an incomplete injury, the clinical efficacy of stem cell therapy might be more obvious.

\section{Characteristics of Diffusion Tensor Imaging in Patients with SCl After Stem Cell Transplantation}

DTI is developed on the basis of DWI and can measure the displacement of water molecules in vivo in at least six directions. It can reflect the diffusion of water molecules more accurately than DWI and provide the functional state of water exchange between tissue components under the tissue's spatial composition and pathophysiological state; furthermore, it can show the direction of the nerve fiber bundle. In this study, the main DTI parameters included the ADC and FA values. The $\mathrm{ADC}$ value reflects the average diffusion ability of water molecules in all directions. The higher the ADC value, the stronger the diffusion ability of water molecules, and the more serious the injury of the spinal cord fiber. A smaller ADC value means that more water molecules can diffuse. ${ }^{25}$ The FA value refers to the proportion of anisotropic component of the water molecule to the whole diffusion tensor. The range of the FA value is $0-1 ; 0$ denotes isotropy, while 1 indicates anisotropy. ${ }^{26}$ The higher the FA value, the better the integrity of the myelin sheath, which can reflect the integrity and conduction function of the nerve fiber bundle and quantitatively express the bundle's pathophysiological state. ${ }^{27}$ Therefore, DTI can be used as one of the indices to observe the therapeutic effect on spinal cord disease following treatment and facilitate a timely and accurate dynamic observation of the 
microscopic changes in the nerve fibers during the process of spinal cord repair. The present study used the changes in ADC and FA values in DTI before and after treatment to evaluate the preclinical efficacy of stem cell transplantation in the treatment of SCI.

In the experimental group, the ADC values of the four patients two months after treatment were significantly lower than before treatment, while their FA values were increased. This change was statistically significant $(P<0.05)$. The ADC values of the three patients in the control group after two months of treatment were also lower than before treatment, and their FA values were increased. However, the difference before and after treatment was not statistically significant. The changes in the experimental group suggest that the changes in spinal cord microstructure before and after treatment were consistent with the principle of spinal cord repair, which indicates that a combination of UC-MSC transplantation and rehabilitation therapy could promote the structural repair of spinal cord nerve fibers in patients with SCI.

In the experimental group, the $\mathrm{ADC}$ and FA values of the lesion layer and the ADC and FA values of the normal layer before and after treatment were compared, respectively. The differences in the ADC and FA values in the lesion layer before and after treatment were found to be greater than in the normal layer. The difference was statistically significant. It was demonstrated that the effect of stem cells transplanted into the subarachnoid space on the lesion area was greater than that on the normal area; this could indicate that this was due to the homing of stem cells. Due to the lack of reports in this area, further research is required.

The biggest limitation in the present study is its small sample size, so the conclusion of this study should be further demonstrated. Due to stopping stem cell transplantation, the experimental group could not continue, and the data of only a few patients were particularly valuable. Small amounts of data lead to the failure of the statistical analysis of clinical evaluation data, and the matching analysis of the DTI data and clinical data was not clear. Furthermore, it was difficult to collect cases and perform follow-ups because of the poor compliance of patients due to the observation of the preclinical effects of the treatment.

\section{Conclusion}

\section{In Summary}

(1) The ADC value and FA value of the patients in the experimental group were significantly changed before and after the treatment, while in the control group, they were not significantly changed. This indicated that the UC-MSCs transplantation combined with comprehensive rehabilitation therapy could help to promote the repair of the spinal nerve fiber structures in patients with SCI. (2) DTI might be able to detect the preclinical changes of UC-MSC transplantation earlier.

\section{Funding}

(1) Major Science and Technology Special Projects in Yunnan Province: Construction of a platform for the promotion and technology transfer of medical, examination, health and wellness services based on life and health (No.2018zf016);(2) Yunnan Rehabilitation Clinical Medical Center (No.zx2019-04-02).

\section{Disclosure}

The authors report no conflicts of interest in this work.

\section{References}

1. Wu QC, Zhang Y, Zhang WX, et al. Advance in riluzole for spinal cord injury (review). Chin J Rehabil Theory Pract. 2018;24 (06):650-653.

2. Du SC, Zhang W, Hu HR, et al. Advances in the use of hypothermia in the treatment of spinal cord injuries. Prog Mod Biomed. 2017;17 (11):2194-2196+2177.

3. Fu CG, Zhao HW, He LJ, et al. New advances in the treatment of spinal cord injury with galactagglutinin 1. Hainan Med J. 2015;26 (16):2405-2406

4. Li HM, Shen CL. Research advances in stem cell therapy for spinal cord injury. Acta Universitatis Medicinalis Anhui. 2019;54 (04):663-666.

5. Levi AD, Anderson KD, Okonkwo DO, et al. Clinical outcomes from a Multi-Center Study of human neural stem cell transplantation in chronic cervical spinal cord injury. J Neurotrauma. 2019;36 (6):891-902. doi:10.1089/neu.2018.5843

6. Silvestro S, Bramanti P, Trubiani O, Mazzon E. Stem cells therapy for spinal cord injury: an overview of clinical trials. Int $J$ Mol Sci. 2020;21(2):659. doi:10.3390/ijms21020659

7. Facon D, Ozanne A, Fillard P, et al. MR diffusion tensor imaging and fiber tracking in spinal cord compression. AJNR. 2005;26:1587-1594.

8. Li CT, Pei L, Sun Y, Hou K, Jf Q. Quality control of magnetic resonance diffusion tensor imaging. Chin J Med Phys. 2020;37 (01):69-74.

9. Shroff G, Dhanda Titus J, Shroff R. A review of the emerging potential therapy for neurological disorders: human embryonic stem cell therapy. Am J Stem Cells. 2017;6(1):1-12.

10. Xu J, Zheng J, Cao YH, et al. Experimental study on transplantation of embryonic stem cells in treating spinal cord injury. China Trop Med. 2015;15(09):1031-1036.

11. Pereira IM, Marote A, Salgado AJ, Silva NA. Filling the gap: neural stem cells as a promising therapy for spinal cord injury. Pharmaceuticals. 2019;12(2):65. doi:10.3390/ph12020065

12. Gao JW, Guo HY, Lv XG, et al. Experimental effect of human umbilical cord mesenchymal stem cell transplantation on acute spinal cord injury repair. J Taishan Med Coll. 2018;39(12):1350-1353.

13. Salewski RP, Mitchell RA, Li L, et al. Transplantation of induced pluripotent stem cell-derived neural stem cells mediate functional recovery following thoracic spinal cord injury through remyelination of axons. Stem Cells Transl Med. 2015;4(7):743-754. doi:10.5966/ sctm.2014-0236 
14. Nazm Bojnordi M, Movahedin M, Tiraihi T, et al. Oligoprogenitor cells derived from spermatogonia stem cells improve remyelination in demyelination model. Mol Biotechnol. 2014;56(5):387-393. doi:10.1007/s12033-013-9722-0

15. Zheng G, Ge M, Qiu G, et al. Mesenchymal stromal cells affect disease outcomes via macrophage polarization. Stem Cells Int. 2017;20(15):47-53.

16. Zhang J, Cui Z, Feng G, et al. Rbm5 and p53 expression after rat spinal cord injury: implications for neuronal apoptosis. Int $J$ Biochem Cell Biol. 2015;60:43-52. doi:10.1016/j. biocel.2014.12.020

17. Cofano F, Boido M, Monticelli M, et al. Mesenchymal stem cells for spinal cord injury: current options, limitations, and future of cell therapy. Int J Mol Sci. 2019;20(11):2698. PMID: 31159345; PMCID: PMC6600381. doi:10.3390/ijms20112698

18. Liau LL, Looi QH, Chia WC, Subramaniam T, Ng MH, Law JX. Treatment of spinal cord injury with mesenchymal stem cells. Cell Biosci. 2020;10(1):112. doi:10.1186/s13578-02000475-3

19. Dasari VR, Veeravalli KK, Dinh DH. Mesenchymal stem cells in the treatment of spinal cord injuries: a review. World J Stem Cells. 2014;6(2):120-133. doi:10.4252/wjsc.v6.i2.120

20. Caron I, Rossi F, Papa S, et al. A new three dimensional biomimetic hydrogel to deliver factors secreted by human mesenchymal stem cells in spinal cord injury. Biomaterials. 2016;75:135-147. doi:10.1016/j.biomaterials.2015.10.024
21. Kao $\mathrm{CH}$, Chen $\mathrm{SH}$, Chio $\mathrm{CC}$, et al. Human umbilical cord blood-derived CD34+cells may attenuate spinal cord injury by stimulating vascular endothelial and neurotrophic factors. Shock. 2008;29(1):49-55. doi:10.1097/shk.0b013e31805cddce

22. Honmou O, Houkin $\mathrm{K}$, Matsunaga $\mathrm{T}$, et al. Intravenous administration of auto serum-expanded autologous mesenchymal stem cells in stroke. Brain. 2011;134(Pt 6):1790-1807. doi:10.1093/ brain/awr063

23. Cl L, Wu Y. Advances of stem cells transplantation for spinal cord injury. Chin J Tissue Eng Res. 2011;15(32):6051-6054.

24. Dedeepiya V, Manjunath S, Murugan P, et al. Autologous bone marrow stem cells in spinal cord injury; our experience in clinical studies, animal studies, obstacles faced and steps for future. J Stem Cells Regen Med. 2010;6(3):177-179.

25. Libro R, Bramanti P, Mazzon E. The combined strategy of mesenchymal stem cells and tissue-engineered scaffolds for spinal cord injury regeneration. Exp Ther Med. 2017;14(4):3355-3368. doi:10.3892/ etm.2017.4939

26. Kwon HG, Su MS, Jang SH. Development of the transcallosal motor fiber from the corticospinal tract in the human brain: diffusion tensor imaging study. Front Hum Neurosci. 2014;8(8):153. doi:10.3389/ fnhum.2014.00153

27. Zhan J, Zhang TJ, Yu CY, et al. The combination of diffusion tensor tractography and fractional anisotropy in evaluating the type of damage on corticospinal tracts due to intracerebral hemorrhage in the basal ganglia. J Clin Radiol. 2016;35:1320-1325.
International Journal of General Medicine

\section{Publish your work in this journal}

The International Journal of General Medicine is an international, peer-reviewed open-access journal that focuses on general and internal medicine, pathogenesis, epidemiology, diagnosis, monitoring and treatment protocols. The journal is characterized by the rapid reporting of reviews, original research and clinical studies

\section{Dovepress}

across all disease areas. The manuscript management system is completely online and includes a very quick and fair peer-review system, which is all easy to use. Visit http://www.dovepress.com/ testimonials.php to read real quotes from published authors. 